
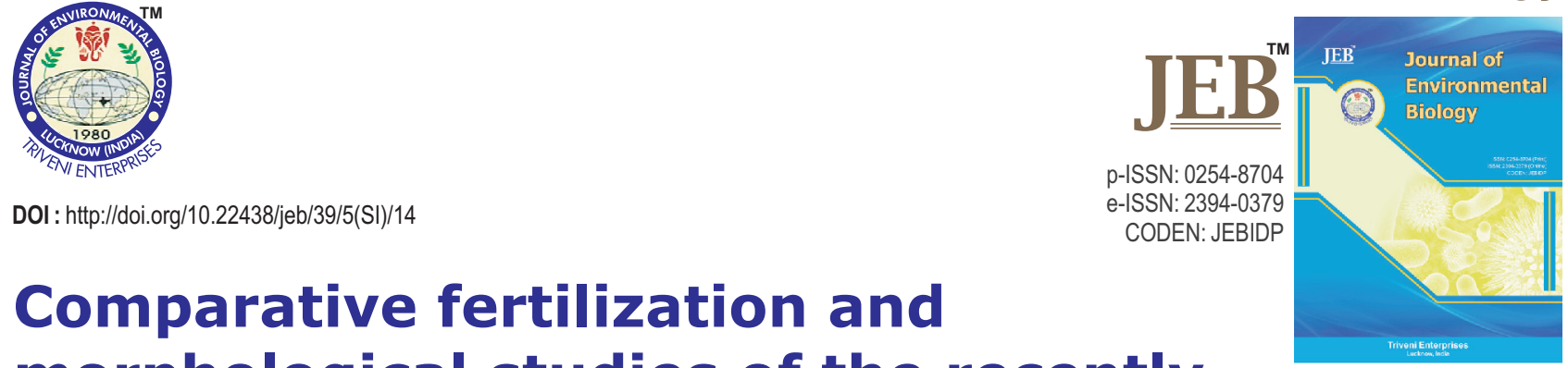

\title{
Comparative fertilization and morphological studies of the recently speciated tropical sea urchins (Echinometra spp.) on the coral reefs of Okinawa and Hawaii
}

Authors Info

M. Aminur Rahman ${ }^{1,3 *}$, Y. Arakaki ${ }^{2}$, Sang-Go Lee ${ }^{1}$ and Fatimah Md. Yusoff ${ }^{3}$

'World Fisheries University Pilot Programme, Pukyong National University (PKNU), 45 Yongso-ro, Nam-gu, Busan 48513, Korea

${ }^{2}$ Department of Tourism, Faculty of International Studies, Meio University, Nago, Okinawa-9058585, Japan

${ }^{3}$ Laboratory of Marine Biotechnology, Institute of Bioscience, Universiti Putra Malaysia, 43400 UPM Serdang, Selangor, Malaysia

*Corresponding Author Email : aminur1963@gmail.com

Key words

Echinometra

Fertilization

Gamete incompatibility

Morphology

Sea urchins

Speciation

Publication Info

Paper received : 20.02.2017

Revised received: 15.05.2017

Re-revised received : 25.06 .2017

Accepted: 28.12.2017

\section{Abstract}

Aim: The Indo-Pacific genus of tropical sea urchin Echinometra is composed of at least five reproductively isolated species. Among them, two sympatric species, the brownish Echinometra sp. C (Ec) and the black Echinometra oblonga (Eo) inhabit Okinawan reef margins and the allopatric black Echinometra sp. $\mathrm{E}(\mathrm{Ee})$ commonly occurs on Hawaiian reef flats. To investigate the mechanism(s) for reproductive isolation and speciation, a detailed cross-fertilization and morphological studies were conducted among the sympatric Ec and Eo and allopatric Ee.

Methodology: Gametes were obtained from three species of sexually matured Echinometra (Ec, Eo and $\mathrm{Ee}$ ) after inducing spawning by injecting of $0.5 \mathrm{M} \mathrm{KCl}$ into the coelomic cavity. Cross-fertilization among them was conducted using all possible combinations of ova and sperm at room temperatures $\left(27-28^{\circ} \mathrm{C}\right)$. Fertilization rate at different sperm concentrations was estimated at 1.25-1.5 hrs after gamete mixing by counting the number of embryos reaching 2-4 cells among the first 100 eggs observed. The morphological characteristics for describing the differences were recorded or measured from Ec Eo and Ee were: color patterns of oral and aboral spines and test, gamete sizes, spicules in the tubefeet and gonads, pedicellaria valve length, Aristotle's lantern, test sizes, spine lengths and pore pairs.

Comparative fertilization and morphological studies of the diverged species of Pacific sea urchins (genus Echinometra)

Results: Cross-fertilization rates with limited sperm concentration were highest between sympatric Ec and Eo, lower between allopatric Ec and Ee, and lowest between allopatric Eo and Ee. The lower fertilization success between these allopatric Hawaiian and Okinawan sea urchins indicates that gamete recognition molecules are diverging due to genetic drift, and not by reinforcement. Such a system might eventually lead to complete gametic incompatibility. Morphological characteristics of gametes, spines, pedicellaria valve length, Aristotle's lantern, and gonad and tubefoot spicules of Ee differed more from those of Eo than Ec, while other characteristics such as color patterns, test sizes and pore pair ratios of Ee were closer to Eo.

Interpretation: The closer affinity of majority of the characteristics of Ee to those of Ec, as well as the relative gamete compatibilities indicate that they evolved into distinct species after the separation of $E$. oblonga.

\section{$\downarrow$}

Two sympatric, the brownish Echinometra sp. C (Ec) and the black Echinometra oblonga (Eo) were collected from Okinawan reef margins, Japan, while the allopatric black Echinometra sp. $E(E e)$ was obtained from Hawaiian reef flats, USA

\section{1}

Matured eggs and sperms were collected from the sexually matured adults of three sea urchin species (Ec, Eo and $\mathrm{Ee})$ through the intracoelomic injection of $0.5 \mathrm{M} \mathrm{KCl}$ \section{7}

Cross-fertilization among the three Echinometra sp. was conducted in a series of 'dry' sperm dilutions $\left(10^{-1}-10^{-7}\right)$ using all possible combinations of ova and sperm at $27-28^{\circ} \mathrm{C}$, and the fertilization rates were estimated and compared $\downarrow$

The morphological characteristics for describing the differences were recorded or measured from Ec, Eo and Ee : color patterns of spines and test, gamete sizes, spicules in tubefeet and gonads, pedicellaria valve length, Aristotle's lantern, test sizes, spine lengths and pore pairs

Mechanisms for maintaining reproductive isolation and speciation among the sympatric Ec and Eo, and allopatric Ee were investigated and discussed accordingly 


\section{Introduction}

Pantropical sea urchins of genus Echinometra diverged into two different lineages 3.3-3.5 million years ago when the Indo-Pacific (IP) lineage separated from the one leading to the neotropical species (McCartney et al., 2000). Since then the IndoPacific lineage has undergone several speciation events. Mayr (1954) noted that both the early phase of geographical speciation (divergence between allopatric populations) and the late phase (highly differentiated species occurring sympatrically) were evident in the genus Echinometra. Allopatric speciation begins with isolation imposed by the environment, either through a complete barrier or through isolation by distance (Slatkin, 1982). In this case, genetic changes after isolation accumulate to limit interbreeding if the extrinsic, geographic barrier should ever break down (Bush, 1975). Sympatric speciation is similar in that it requires the accumulation of enough genetic differences that assortative mating evolves in concert with genetic changes. However, these concerted genetic changes must take place within populations rather than between them (Palumbi, 1998). Among different species in different habitats, there are different types of reproductive isolation. Examining the genetic, morphological, physiological, and ecological bases for reproductive isolation has been a critically important part of understanding the speciation process in the genus Echinometra (Palumbi, 1998).

Recent biological, ecological, morphological, molecular and hybridization studies revealed the existence of four closely related species of tropical sea urchins (Echinometra spp.) on the intertidal reefs of the warm Indo-West Pacific, designated as Echinometra sp. A, B, C and D (Uehara et al., 1990, 1991; Arakaki and Uehara, 1991; Matsuoka and Hatanaka, 1991; Nishihira et al., 1991; Palumbi and Metz, 1991; Metz et al., 1994; Metz and Palumbi, 1996; Palumbi, 1996; Aslan and Uehara, 1997; Palumbi et al., 1997; Arakaki et al., 1998; Rahman et al., 2000, 2001, 2004 , 2012; Landry et al., 2003). Molecular phylogenies indicate that these species split from one another 1-3 million years ago (Palumbi, 1996). Recently, Echinometra sp. B is named as Echinometra mathaei (Em) (Arakaki et al., 1998), whereas Echinometra sp. D is recognized as Echinometra oblonga (Eo) species complex, which probably consists of three cryptic species (Arakaki et al., 1998). However, the remaining two species, Echinometra sp. A and Echinometra sp. C are still to be formally described and scientifically named (Rahman et al., 2001; Rahman and Uehara, 2003). Among these four species, $E$. oblonga, a black species occupies from Mauritius in the Indian Ocean to Isa del Coco in the Eastern Pacific. Typically this species inhabits burrows above the mean low water level, in microhabitats highly exposed to strong wave action (Kelso, 1970; Nishihira et al., 1991). This habitat preference correlates with species-specific physiological adaptations providing resistance to extreme conditions such as high and low temperature, salinity changes (Arakaki and Uehara, 1991) and strong shearing action of waves on gametes (Mead, 1996). However, based on monophyletic mtDNA lineages (Palumbi and Metz, 1991), differences in allozymes (Matsuoka and Hatanaka, 1991), reproductive incompatibilities (Uehara et al., 1990; Palumbi and Mez, 1991; Metz et al., 1994), differences in sperm morphology and sperm-egg binding protein during fertilization (Metz and Palumbi, 1996; Landry et al., 2003), and displacement of reproductive characters (Geyer and Palumbi, 2003), this species has throughly been described from Japan and Hawaii. Recent studies of the morphological characteristics revealed that black Echinometra in the IWP should be grouped into three subgroupings such as: Mauritian/Indonesian/Okinawan/Boninian, Guamanian and Hawaiian individuals. These three subgroupings are considered to be independent species forming a complex species group (Arakaki and Uehara, 1999; Arakaki, 2000). Recently, the 1st group has been recognized to be as $E$. oblonga (Eo), whereas the remaining two (Hawaiian and Guamanian) groups are yet to be described. However, Uehara et al. (1996) considered the Hawaiian black urchin as Echinometra sp. $E(E e)$.

Selection in gamete recognition genes shows geographic patterns suggestive of reinforcement. In sea urchins, the acrosomal protein bindin attaches sperm to the egg and evolves quickly between species (Metz and Palumbi, 1996; Biermann, 1998). However genera (Echinometra, Strongylocentrotus and Heliocidaris) showing many sequence rearrangements and indication of positive selection in "hotspot" regions on either side of the core, are broadly sympatric (Metz and Palumbi 1996; Biermann, 1998; Debenham et al., 2000; Geyer and Palumbi, 2003; Zigler et al., 2003) whereas genera with allopatric distributions (e.g., Arbacia and Tripneustes) show fewer sequence rearrangements and no evidence for positive selection and little reproductive isolation (Metz, et al., 1998; Zigler and Lessios, 2003, 2004). In the genus Echinometra, species are broadly sympatric, with co-existing species found on the same reef bench (Kelso, 1970; Russo, 1977; Tsuchiya and Nishihira 1984; Nishihira et al., 1991). Although species often exhibit slightly different ecological ranges, many individuals are found to be in mixed populations. In such cases, gamete mixing is probably common and reproductive isolation seems to be drive from gamete incompatibility (Palumbi and Metz, 1991).

As Echinometra distributions are widespread and patchy, however, it is possible to find allopatric populations of species that are typically sympatric. For example, Eo and Ec are patchily sympatric on reefs of Okinawa (Western Pacific); Ec does not occur in Hawaii (Central Pacific), although both Em and Eo do (Palumbi et al., 1997). Eo and Ec show very high rates of interspecific fertilization in the laboratory (Uehara et al., 1990), yet hybrids are rarely found in the field (Palumbi, 1997). The other congeneric species, Em and Ea do not readily cross-fertilize with either of the two species. To investigate the potential of reproductive isolation and speciation, were conducred a detailed cross-fertilization and morphological studies among the sympatric Ec and Eo and allopatric Ee. 


\section{Materials and Methods}

Sample collection and maintenance: Live adult individuals of $\mathrm{Ee}$ (identified on the basis of a black test and spines: Uehara et al, 1996; Arakaki and Uehara, 1999) collected from the Turtle Bay (Hawaii) during mid July 2003, were transported to Sesoko Marine Research Center where they were cultured in aquaria with flow-through sea water, as described by Rahman et al. (2000). Coral skeletons covered with encrusting coralline algae served as food. After a culture period of nearly one month and a half, the urchins attained sexual maturity. Mature adults of the two sympatric species of Okinawan Echinometra, brownish black Ec (Uehara, 1990) and completely black Eo (Uehara, 1990; Arakaki and Uehara, 1999) were sampled along the coast at Sesoko Island of Okinawa Prefecture, Japan. The collected live individuals along with Ee specimens were transported to the laboratory Biology and Marine Science, University of the Ryukyus, Okinawa, and were reared in sea water aquaria before being used for spawning.

Cross-fertilization experiments: Both female and male gametes were collected from all the 3 species of Echinometra sea urchins ( $\mathrm{Ec}, \mathrm{Eo}$ and $\mathrm{Ee}$ ) by intercoelomic injection with $0.5 \mathrm{M} \mathrm{KCl}$. Eggs were obtained from female urchins in sterilized filtered seawater (SFSW), while "dry" sperm, in its most concentrated form, were collected directly by pipettes from the gonopores of male individuals and kept in refrigerator at $4-5^{\circ} \mathrm{C}$ for not more than $2 \mathrm{hrs}$ before use. Cross-fertilization of the three Echinometra sp. was conducted using all possible combinations of ova and sperm at room temperatures $\left(27-28^{\circ} \mathrm{C}\right)$. For consistency, when referring to the heterospecific crosses, the maternal species is named first. (e.g., Ec x Eo means that sperm from a male of Eo fertilized ova from a female of $\mathrm{Ec}$ ). For each of the heterospecific fertilization, a conspecific fertilization by use of ova from the same female was also conducted as a control. Eggs from the gravid females were diluted in SFSW containing 3500-4000 eggs $\mathrm{ml}^{-1}$. In order to determine fertilization rates at various homogametic and heterogametic sperm concentrations, $0.1 \mathrm{ml}$ aliquots of diluted egg suspension (350-400 eggs) were kept in small vials containing $0.8 \mathrm{ml}$ of SFSW. "Dry" sperm ( $10^{\circ}$ dilution) that were collected freshly from the urchins was diluted in a series of 10 -fold i.e., $10^{-1}-10^{-7}$. Afterwards, $0.1-\mathrm{ml}$ aliquots from each of these sperm solution were put into the vials containing $0.9-\mathrm{ml}$ egg suspensions to maintain the final volumes of $1.0 \mathrm{ml}$. For example, mixing a $0.1 \mathrm{ml}$ aliquot of $10^{-1}$ undiluted sperm with a $0.9 \mathrm{ml}$ egg suspension yielded a $10^{-2}$ diluted concentration of sperm. This procedure resulted in series ranging from $10^{-2}-10^{-8}$ diluted concentration of sperm. Sperm concentration from $10^{-4}$ dilution was first measured by hemacytometer counts of six independently diluted sperm from each species and then adjusted with the dilution series. After $10 \mathrm{~min}$ of gamete mixing, excess sperm were removed by $4-5$ consecutive washes with SFSW and the eggs were then resuspended in $5 \mathrm{ml}$ of FSW into the vial for incubation. Percent fertilization was determined by counting the number of embryos, attaining 2-4 cells among the 100 eggs observed. In total, six replicate crosses were conducted among the three species and in each cross, only gametes from new individuals were used.

Morphological characteristics: The morphological characteristics for describing the differences were recorded or measured from Ec, Eo and Ee were: Color patterns of oral and aboral spines and test, gamete sizes, spicules in the tubefeet and gonads, pedicellaria valve length, Aristotle`s lantern, test sizes and spine lengths and pore pairs.

Color patterns of the body and spine of live adult urchins were observed following the color book of Kornerup and Wanscher (1978). Gamete sizes (egg diameter and sperm-head length) were measured from the sexually mature $\mathrm{Ec}, \mathrm{Eo}$ and $\mathrm{Ee}$ using a differential microscope following Amy (1983) and Rahman etal. (2002) (with eggs at 400x in a slide well, sperm at 1000x on a flatslide).

The spicules of tubefoot and gonad of the urchins were thoroughly examined. A small piece of the gonadal tissue was clipped off using forceps and immersed in distilled water. Samples were first treated with $10 \% \mathrm{KOH}$ and then squashed on a slide glass with a cover slip, and finally observed under an objective microscope $(10 \times 10)$. Several tubefeet were clipped off with a forcep, the morphology of the spicules was then investigated by the same methods as above.

For easy collection of the pedicellariae, all spines around the body were removed. The pedicellariae were plucked from the test near peristome and ambital area. Soft tissues from the pedicellariae were removed by treating them with $10 \%$ sodium hypochlorite solution (household bleach) and the clear pedicellariae were rinsed with three changes of distilled water. The valve lengths (VLs) of all 4 types of pedicellariae (tridentate, globiferous, ophiocephalous and triphyllus) were then measured under a compound microscope $(10 \times 10)$ with a presetting micrometer.

After removing the Aristotle's lantern from the live specimens, the diameter and length of the pyramid, the length and width of the teeth between the hard oral end and the inferior oral end of the pyramid were measured with a caliper. For measuring spine length, 30 spines were randomly selected from the equator of the test. Before measuring the test morphologies, the urchins were first treated with $30 \%$ sodium hypochlorite solution until all the spines and tissues were removed from the test. The tests of echinoids in the family Echinomatridae were oblong, length (TL), width (TW), height (TL) and volume (TV) of test, and length and width of peristome and periproct were measured with calipers. Test shape and flatness were calculated using the ratio of test height to test length (TH/TW) and test width to test length (TW/TL), respectively. 
The number and percentage of various pore pairs on every ambulacral plate (of the five ambulacra from the apical to the peristomial system in a denuded test of the urchins) were counted under a dissecting microscope.

Data analyses: Before statistical analyses, percentage data were arcsine transformed, and the replicate experiments in which none of the eggs or all eggs fertilized were given a numerical value of $1 / 4 n$ and $1-1 / 4 n$ ( $n$ is the number of observations) to improve the transformation (Zar, 1996). All data were analyzed by one-way ANOVA followed by Dunn's multiple comparison test. The significant level was fixed at 0.05 . Untransformed data are shown in respective tables and figures.

\section{Results and Discussion}

Fertilization success of conspecific and heterospecific crosses using the gametes of Eo, Ee and Ec were highly dependent on sperm concentrations, i.e., higher the sperm concentration, higher the fertilization rate (Table 1). At higher sperm concentrations $\left(10^{7}-10^{9}\right.$ sperm $\left.\mathrm{ml}^{-1}\right)$, the percent fertilization of conspecific crosses (Eo x Eo, Ee x Ee and Ec x Ec) was identical $(100 \%)$ but progressively decreased with decreasing sperm concentrations in a manner that Eo $x$ Eo showed slightly higher fertilization rates followed by those of Ee $x$ Ee and Ec x Ec in that order. Fertilization rates in heterospecific crosses at higher sperm concentrations $\left(10^{8}-10^{9} \mathrm{sperm} \mathrm{m}^{-1}\right)$ were $100 \%$, except for Eo x Ee and Ee x Eo crosses where $98.2 \%$ and $96.2 \%$ fertilizations were achieved at a concentration of $10^{8}$ sperm $\mathrm{ml}^{-1}$. Asymmetry in fertilization rates were observed in heterospecific crosses at $10^{7}$ spem ml in a way that Ec $\times$ Eo showed higher rate $(98.8 \%)$ followed by Eo $x \mathrm{Ec}(95.7 \%)$, Ec $\times$ Ee $(94.7 \%)$ and Eex Ec (92.3\%), while significantly lower (Dun's test, $p<0.5 \%)$ fertilization rates were obtained in $\operatorname{Eox} \operatorname{Ee}(79.8 \%)$ and Ee $x$ Eo $(74.2 \%)$, respectively. At a limited sperm density $\left(10^{6}\right.$ sperm $\mathrm{ml}^{-1}$ ), in which homospermic crosses achieved $100 \%$ or near $100 \%$ fertilization success, mean fertilization rates obtained in heterospermic Ee x Eo (43\%) and Eo x Ee (45.3\%) crosses were lower (Dunn's test, $p<0.05$ ) than the values obtained in Eex Ec $(69.2 \%)$, Ec $x$ Ee $(72.7 \%)$, Eo $x$ Ec $(81.8 \%)$ and Ec $\times$ Eo $(85.3 \%$ ) crosses, respectively (Table 1 ). In the condition of lower sperm concentrations $\left(\leq 10^{6}\right.$ sperm), heterospermic crosses exhibited the same trends but consequently lower fertilization rates than those found in homospermic crosses. At limited and lower concentrations of sperm, gametes of allopatric Ee showed significantly lower fertilization rates with the gametes of sympatric Eo than those of Ec.

Cross-fertilization rates between the sympatric Ec and Eo in either direction were higher compared to those between $E c$ and allopatric Ee under limited and lower sperm concentrations, whereas these values were comparatively low with the eggs of Eo and sperm of Ee and vice versa. This strong impediment to fertilization indicates the presence of a gamete recognition protein binding system, as reported by Metz et al. (1994) and
Metz and Palumbi (1996). The discriminations in fertilization success between the Okinawan (Western Pacific) and Hawaiian (central Pacific) black Echinometra indicated that gamete recognition molecules are diverging due to genetic drift and not by active reinforcement. However, the higher fertilization rates in the sympatric Ec and Eo revealed that prezygotic barrier by gametic incompatibility hardly appears to be present between these two species, or among most of the putative morphospecies of Echinometra that co-exist in Okinawa (Uehara et al., 1990; Aslan and Uehara, 1997; Rahman et al., 2000, 2001, 2004, 2012; Rahman and Uehara, 2004). On the other hand, the fertilization biology of these echinoids presents some surprising complexities that run counter to expectations. The two reef margin species, Eo and Ec, do not co-occur throughout their respective ranges, and Gayer and Palumbi (2003) found that there is more genetic separation of bindin genes where they are sympatric than where they are allopatric. This finding suggests that where the two species co-occur, they are currently undergoing reproductive character displacement and separation via gamete recognition. Nevertheless, at Okinawa where they co-occur, we found that fertilization levels over a wide range of sperm concentrations are nearly identical between conspecific and heterospecific crosses (Uehara et al., 1990; Rahman et al., 2012). Similarly, two closely related species of asteriods under the genus, Patiriella do not have gamete incompatibility when they are in sympatric (Byrne and Anderson, 1994). Therefore, reproductive isolation and speciation might have been happened prior to the evolution of gametic incompatibility because recognition molecules between egg and sperm usually do accumulate over time as the species undergo diversification (McCartney and Lessios, 2002).

Asymmetric gamete incompatibility in sympatric versus allopatric and allopatric versus sympatric species are evidenced from the present study. Species of sea urchin genus Echinometra found on the two coasts of Panama are recently diverged and only partially isolated by incomplete barriers to interspecific fertilization. Extensive studies on cross-fertilization revealed incompatibility between the eggs of Atlantic $E$. lucunter and the sperm of other two neotropical species, whereas eggs of its sympatric congener $E$. viridis and allopatric $E$. vanbrunti are largely compatible with heterospecific sperm (Lessios and Cunningham, 1990; McCartney and Lessios, 2002). A high percentage of eggs of Strongylocentrotus droebachiensis are fertilized by sperm of its sympatric (but bathymetrically displaced) congener, $S$. pallidus, but the reciprocal cross of $S$. pallidus eggs and $S$. droebachiensis sperm produces very low percent fertilization (Strathmann, 1981; Biermann et al., 2004). S. purpuratus sperm fertilize high proportion of $S$. droebachiensis eggs even though few of the sperms react to $S$. droebachiensis egg jelly, and eggs of $S$. droebachiensis are highly fertilizable in general (Levitan, 2002). Oyster species in the genus Crassostrea that co-occur in Japan show an asymmetric block to fertilization (Banks et al., 1994). Percent fertilization of eggs from white abalones (Haliotis sorenseni) by sperm of another California 
Table 1: Comparison of fertilization levels in conspecific and heterospecific crosses among Echinometra oblonga (Eo), Echinometra sp. E (Ee) and Echinometra sp. C (Ec). For brevity, maternal species is placed first. Six replicate fertilization experiments were conducted and in each cross, fresh gametes from each species were used for each replicate $(n=6)$. Percentage values indicate mean $\pm S D$, while ranges are in parentheses

\begin{tabular}{|c|c|c|c|c|c|c|c|}
\hline \multirow[t]{2}{*}{ Crosses } & \multicolumn{7}{|c|}{ Sperm concentration (sperm ml l $^{-1}$} \\
\hline & $10^{9}$ & $10^{8}$ & $10^{7}$ & $10^{6}$ & $10^{5}$ & $10^{4}$ & $10^{3}$ \\
\hline EcxEc & $100^{a^{*}}$ & $100^{\mathrm{a}}$ & $100^{\mathrm{a}}$ & $\begin{array}{l}98.5 \pm 1.5^{\mathrm{a}} \\
(96.0-100.0)\end{array}$ & $\begin{array}{l}69.8 \pm 6.0^{\mathrm{a}} \\
(60.0-77.0)\end{array}$ & $\begin{array}{l}34.8 \pm 3.7^{a} \\
(30.0-40.0)\end{array}$ & $\begin{array}{l}18.0 \pm 2.8^{\mathrm{a}} \\
(14.0-22.0)\end{array}$ \\
\hline EexEe & $100^{\mathrm{a}}$ & $100^{\mathrm{a}}$ & $100^{\mathrm{a}}$ & $\begin{array}{l}99.0 \pm 1.3^{a} \\
(97.0-100.0)\end{array}$ & $\begin{array}{l}72.3 \pm 6.1^{a} \\
(62.0-80.0)\end{array}$ & $\begin{array}{l}37.3 \pm 3.4^{a} \\
(33.0-42.0)\end{array}$ & $\begin{array}{l}19.3 \pm 3.1^{\mathrm{a}} \\
(14.0-22.0)\end{array}$ \\
\hline EoxEo & $100^{\mathrm{a}}$ & $100^{\mathrm{a}}$ & $100^{\mathrm{a}}$ & $\begin{array}{l}99.5 \pm 0.9^{\mathrm{a}} \\
(98.0-100.0)\end{array}$ & $\begin{array}{l}74.8 \pm 7.4^{\mathrm{a}} \\
(66.0-85.0)\end{array}$ & $\begin{array}{l}39.3 \pm 3.8^{\mathrm{a}} \\
(35.0-45.0)\end{array}$ & $\begin{array}{l}20.5 \pm 2.9^{\mathrm{a}} \\
(15.0-24.0)\end{array}$ \\
\hline EcxEo & $100^{\mathrm{a}}$ & $100^{\mathrm{a}}$ & $\begin{array}{l}98.8 \pm 1.2^{a} \\
(97.0-100.0)\end{array}$ & $\begin{array}{l}85.3 \pm 4.2^{b} \\
(78.0-90.0)\end{array}$ & $\begin{array}{l}48.5 \pm 3.8^{b} \\
(44.0-55.0)\end{array}$ & $\begin{array}{l}22.5 \pm 3.1^{b} \\
(18.0-26.0)\end{array}$ & $\begin{array}{l}9.3 \pm 2.2^{b} \\
(6.0-12.0)\end{array}$ \\
\hline EoxEc & $100^{\mathrm{a}}$ & $100^{\mathrm{a}}$ & $\begin{array}{l}95.7 \pm 2.1^{\mathrm{a}} \\
(92.0-98.0)\end{array}$ & $\begin{array}{l}81.8 \pm 6.7^{b} \\
(70.0-88.0)\end{array}$ & $\begin{array}{l}43.0 \pm 3.6^{b} \\
(38.0-48.0)\end{array}$ & $\begin{array}{l}19.2 \pm 3.3^{b} \\
(16.0-24.0)\end{array}$ & $\begin{array}{l}6.2 \pm 1.2^{b} \\
(5.8-8.0)\end{array}$ \\
\hline EcxEe & $100^{\mathrm{a}}$ & $100^{\mathrm{a}}$ & $\begin{array}{l}94.7 \pm 2.9^{\mathrm{a}} \\
(90.0-98.0)\end{array}$ & $\begin{array}{l}72.7 \pm 4.9^{c} \\
(68.0-80.0)\end{array}$ & $\begin{array}{l}37.2 \pm 4.2^{c} \\
(32.0-44.0)\end{array}$ & $\begin{array}{l}15.0 \pm 2.9^{c} \\
(13.0-19.0)\end{array}$ & $\begin{array}{l}2.2 \pm 1.0^{c} \\
(1.0-3.0)\end{array}$ \\
\hline EexEc & $100^{\mathrm{a}}$ & $100^{\mathrm{a}}$ & $\begin{array}{l}92.3 \pm 2.3^{\mathrm{a}} \\
(90.0-96.0)\end{array}$ & $\begin{array}{l}69.2 \pm 5.6^{c} \\
(62.0-78.0)\end{array}$ & $\begin{array}{l}35.3 \pm 3.1^{c} \\
(32.0-40.0)\end{array}$ & $\begin{array}{l}13.8 \pm 2.9^{c} \\
(10.0-18.0)\end{array}$ & $\begin{array}{l}1.5 \pm 0.6^{c} \\
(1.0-2.0)\end{array}$ \\
\hline EoxEe & $100^{\mathrm{a}}$ & $\begin{array}{l}98.2 \pm 1.6^{\mathrm{a}} \\
(96.0-100.0)\end{array}$ & $\begin{array}{l}79.8 \pm 3.0^{b} \\
(76.0-84.0)\end{array}$ & $\begin{array}{l}45.3 \pm 3.6^{d} \\
(40.0-50.0)\end{array}$ & $\begin{array}{l}13.5 \pm 2.7^{d} \\
(10.0-17.0)\end{array}$ & $\begin{array}{l}2.2 \pm 1.2^{d} \\
(1.0-4.0)\end{array}$ & $0.0^{\mathrm{d}}$ \\
\hline EexEo & $100^{\mathrm{a}}$ & $\begin{array}{l}96.2 \pm 2.5^{\mathrm{a}} \\
(92.0-99.0)\end{array}$ & $\begin{array}{l}74.2 \pm 4.6^{\mathrm{b}} \\
(68.0-80.0)\end{array}$ & $\begin{array}{l}43.0 \pm 3.7^{d} \\
(38.0-48.0)\end{array}$ & $\begin{array}{l}11.7 \pm 2.1^{d^{\prime}} \\
(9.0-14.0)\end{array}$ & $\begin{array}{l}1.3 \pm 0.5^{\mathrm{d}} \\
(1.0-2.0)\end{array}$ & $0.0^{d}$ \\
\hline
\end{tabular}

"Mean values in the same column with common superscripts are not significantly different (Dunn's test, $p>0.05$ )

Table 2: Comparison of gamete sizes from sexually mature Echinometra oblonga (Eo), Echinometra sp. E (Ee) and Echinometra sp. C (Ec). Six individual urchins were examined from each species for each sex with 25 eggs and 25 sperms from each individual; mean \pm SD in $\mu \mathrm{m}$ with ranges in parentheses

\begin{tabular}{llll}
\hline Gametes & Eo $(\boldsymbol{\mu m})$ & Ee $(\boldsymbol{\mu m})$ & Ec $(\boldsymbol{\mu m})$ \\
\hline Egg diameter & $75.85 \pm 1.62^{\mathrm{a}^{\mathrm{t}}}(73.16-78.12)$ & $74.04 \pm 1.22^{\mathrm{ab}}(71.92-76.88)$ & $72.93 \pm 1.36^{\mathrm{b}}(70.68-75.64)$ \\
Sperm-head length & $8.14 \pm 0.61^{\mathrm{a}}(7.00-9.50)$ & $6.53 \pm 0.55^{\mathrm{ab}}(5.50-7.50)$ & $5.87 \pm 0.45^{\mathrm{b}}(5.00-7.00)$ \\
\hline
\end{tabular}

"Mean values in the same row with common superscripts are not significantly different (Dunn's test, $p>0.05$ )

species, $H$. rufescens, is close to $100 \%$, but is much lower in the reciprocal cross (Leighton and Lewis, 1982). In one case, asymmetric incompatibility exists between sympatric species that are distantly related. Close to $100 \%$ of the eggs of the Hawaiian sea urchin Colobocentrotus atratus can be fertilized by the sperm of sea urchins Echinometra mathaei, Pseudobolatia indiana and Tripneustes gratilla (the later of two of which are in a different family). In contrast, the same concentration of $C$. atratus sperm fertilizes a much smaller percentage of eggs in the reciprocal crosses (Branham, 1972). Kaneshiro (1980) suggested that behavioral isolation evolves as a byproduct of disruptive or directional selection in allopatry, and its asymmetry is due to drift and founder effects in one but not both of the descendent populations. In an analogous fashion, asymmetric barriers to fertilization could emerge as an accident of history, such as a bottleneck in one of the two sister species, then become exaggerated as selection within the bottlenecked population promoted co-evolutionary changes of sperm and eggs, the mechanisms of which need to be examined in order to explain how species integrity is maintained in these closely related species.

The color pattern of both the spine and test of Ec was brownish-dark and each spine had a clear white ring at the base of it, while Eo was completely dark in test color and base of each spine had a faded white basal ring. Ee was more or less similar to Eo in experiencing uniformly dark spines and test and base of each spine had a faded white ring.

Gamete sizes of Eo, Ee and Ec were different (Table 2). Egg diameter of Eo was largest, whereas the Ec eggs were smallest, the values of which differed significantly (Dunn's test, $p$ $<0.05)$. Ee contained intermediate-sized eggs that were not significantly different (Dunn's test, $p>0.05$ ) from the eggs of Eo 
Table 3: Types and percentages of spicule characteristics in tubefeet and gonads of Echinometra oblonga (Eo), Echinometra sp. E (Ee) and Echinometra sp. C (Ec). Six individual urchins were examined from each species with 10 tubefeet and 10 gonadal tissues from each individual; mean \pm SD in percentage including ranges in parentheses

\begin{tabular}{llll}
\hline Types of spicule & Eo $(\%)$ & Ee $(\%)$ & Ec $(\%)$ \\
\hline Tubefoot spicules & & & \\
Triradiate & $90.54 \pm 1.30^{\mathrm{b}}(88.83-92.38)$ & $97.05 \pm 0.80^{\mathrm{a}}(95.90-97.80)$ & $100^{\mathrm{a}^{*}}$ \\
Bihamate & $3.77 \pm 0.63^{\mathrm{a}}(2.86-4.37)$ & $1.04 \pm 0.25^{\mathrm{b}}(0.63-1.23)$ & $0^{\mathrm{c}}$ \\
Triradiate-bihamate & $5.69 \pm 0.76^{\mathrm{a}}(4.76-6.80)$ & $1.91 \pm 0.62^{\mathrm{b}}(1.28-2.87)$ & $0^{\mathrm{c}}$ \\
& & & \\
Gonad spicules & & & $94.01 \pm 0.89^{\mathrm{a}}(92.55-94.85)$ \\
Triradiate & $84.52 \pm 1.72^{\mathrm{b}}(83.12-93.42)$ & $92.30 \pm 0.68^{\mathrm{a}}(91.49-86.67)$ & $5.07 \pm 0.58^{\mathrm{b}}(4.18-5.34)$ \\
Spindle & $8.00 \pm 0.7^{\mathrm{a}}(6.93-8.96)$ & $5.84 \pm 0.61^{\mathrm{b}}(4.78-6.44)$ & $1.08 \pm 0.23^{\mathrm{b}}(0.88-1.54)$ \\
Bihamate & $2.88 \pm 0.58^{\mathrm{a}}(2.16-3.69)$ & $1.86 \pm 0.22^{\mathrm{b}}(1.55-2.14)$ & $0^{\mathrm{b}}$ \\
Spindle-triradiate & $4.60 \pm 0.61^{\mathrm{a}}(3.77-5.26)$ & $0^{\mathrm{b}}$ & \\
\hline
\end{tabular}

Mean values in the same row with common superscripts are not significantly different (Dunn's test, $p>0.05$ )

Table 4: Valve length $(\mathrm{VL})$ of four types of pedicellariae in Echinometra oblonga (Eo), Echinometra sp. $\mathrm{E}(\mathrm{Ee})$ and Echinometra sp. C (Ec). Six individual urchins were examined from each species with 10 pedicellariae of each type from each individual; mean \pm SD in $\mu$ m including ranges in parentheses

\begin{tabular}{llll}
\hline Pedicellaria type & Eo $(\boldsymbol{\mu m})$ & Ee $(\mu \mathrm{m})$ & Ec $(\mu \mathrm{m})$ \\
\hline Tridentate & $665.00 \pm 31.07^{\mathrm{c}}(620.00-630.00)$ & $780.17 \pm 31.8^{\mathrm{b}}(740.00-850.00)$ & $881.33 \pm 33.25^{\mathrm{a}^{*}}(840.00-950.00)$ \\
Globiferous & $594.88 \pm 26.33^{\mathrm{c}}(540.00-650.00)$ & $622.85 \pm 24.90^{\mathrm{b}}(570.00-670.00)$ & $642.82 \pm 26.76^{\mathrm{a}}(580.00-690.00)$ \\
Ophiocephalous & $453.17 \pm 28.24^{\mathrm{c}}(410.00-500.00)$ & $511.33 \pm 27.18^{\mathrm{b}}(460.00-560.00)$ & $545.17 \pm 26.74^{\mathrm{a}}(490.00-590.00)$ \\
Triphyllous & $110.33 \pm 17.77^{\mathrm{c}}(80.00-140.00)$ & $131.33 \pm 20.31^{\mathrm{b}}(100.00-160.00)$ & $146.50 \pm 22.55^{\mathrm{a}}(110.00-180.00)$ \\
\hline
\end{tabular}

Mean values in the same row with common superscripts are not significantly different (Dunn's test, $p>0.05$ )

and Ec. The size of sperm heads also differed significantly (Dunn's test, $p<0.05$ ) between Eo and Ec, but both of them were did not differed significantly from Ee. Despite these differences, gametes sizes of Ee showed closer values to Ec than those of Eo (Table 2).

Tubefoot spicules in Ec were always triradiate $(100 \%)$, whereas those in Ee were almost triradiate (97\%), followed by triradiate-bihamate $(2 \%)$ and bihamete $(1 \%)$. Tubefoot spicules of Eo were triradiate $(91 \%)$, triradiate-bihamate $(6 \%)$ and bihamate $(4 \%)$. However, the proportions of spicules in Ee were significantly different (Dunn's test, $p<0.05$ ) from Eo and tended towards Ec. The spicules of gonad in Ec were almost triradiate $(94 \%)$, spindle $(5 \%)$ and a very negligible proportion of bihamate (1\%) (Table 3), whereas those in Ee were nearly triradiate (92\%), spindle $(6 \%)$ and bihamate $(2 \%)$. Gonad spicules in Eo were triradiate $(85 \%)$, spindle $(8 \%)$, spindle-triradiate $(4 \%)$ and bihamate $(3 \%)$. Similar to the tubefoot spicules, the proportion of the gonad spicules of Ee differed significantly (Dunn's test, $p<$ 0.05 ) from Eo but showed closer relations to Ec (Table 3).

The pedicellariae found in three species were tridentate, globiferous, ophiocephalous and triphyllus. Only the valve length (VL) of all four types was measured and compared among species. As shown in Table 4, all four types of pedicellaria VL were significantly (Dunn's test, $p<0.05$ ) larger in Ec followed by Ee and Eo in that order. Despite the three species differed in their pedicellaria VLs, the values of Ee maintained closer affinities to the values of $E c$.

Aristotle's lantern length (ALL) of Ec was significantly ( $p<$ 0.05 ) larger than that of Eo, with the lengths in Ee also being significantly different and tending towards the length of $\mathrm{Ec}_{\mathrm{c}}$ (Table 5). Similar results were also observed in Aristotle's lantern diameter (ALD) and Teeth length (TEL). The Teeth width (TEW) of Ec and Ee did not differ significantly (Dunn's test, $p>0.05$ ), but both of them differed significantly from the TEW of Eo (Table 5).

The length and thickness (base, middle and tip) of spines of the adult urchins were measured and compared among the three species (Table 6). Mean values for all these parameters were highest in Ee and smallest in Eo. Although statistically significant differences were recognized in all parameters among Ec, Ee Eo, except the thickness of the tip of spines where Ee had significantly larger values than those of $E_{c}$ and $E 0$, but both $E c$ and Eo did not differ significantly (Dunn's test, $p>0.05$ ) and showed closer proximity with each other. 
Test morphologies in terms of length, width, height and volume including the length and width of peristome and periproct of Ec, Ee and Eo were measured from the clean denuded test of adult urchins (Table 7). Mean values for all these parameters were largest in Ec followed by Ee, while the values were smallest in Eo. Although statistically significant differences were found in all the above morphometric characters among the three species, the values of Ee were closer to Eo than those of Ec.

The percentages of pore pairs on amlulacral plates are shown in Table 8. No significant differences (Dunn's test, $p>0.05$ ) in very small proportions of one- two-, six-, seven- and eight pore pairs were found among the three species (Table 8). The mean percentages of four-pore pairs in all the three groups were highest $(42.02 \%$ to $61.18 \%)$, followed by three-pore pairs $(21.94 \%$ to $28.95 \%$ ) and five-pore pairs (9.24 to $26.58 \%$ ). The three pore pair ratios were significantly higher in Ee, followed by Ec and Eo in that order. The major striking and significant differences (Dunn's test, $p<0.05$ ) were recognized in the proportions of each of the fourand five pore pairs among the three species, despite, the fact that the Ee showed proportions nearly closer to Eo.

Overall, the morphological characteristics of gametes, spines, pedicellaria valve length, Aristotle's lantern and spicules of gonad and tubefeet of Ee were different from Eo but showed closer relations to Ec, while other characteristics such as color patterns, test sizes and pore pair ratios of Ee were closer to Eo. Thus, these species exhibit greater differences in majority of the characters in areas of sympatric contact than they do in areas of allopatry, which are in agreement with the findings of character displacement (Brown and Wilson, 1956; Grant, 1972). However, the closer affinity of majority of the characteristics of Ee to those of Ec indicates the possibility that they were recently evolved into distinct species in the Indo-Pacific. However, character displacement can arise as a secondary effect of environmental adaptation (stickle-backs: Rundle and Schluter, 1998; Rundle et al., 2000, Drosophila: Rice and Salt, 1990; Cicada: Marshal and Cooley, 2000; Simon et al., 2000; Rhagoletis: Bush, 1969; Bush and Smith, 1998). Although both E. oblonga and E. sp. C are generally found in mixed populations in the high intertidal zone, $E$. oblonga tends to be most abundant in areas with high wave action, whereas $E$. sp. C tends to be most abundant in calm, back reef environments (Russo, 1977; Tsuchiya and Nishihira, 1984). Wave turbulence can have a significant effect on fertilization efficiency (Mead, 1996) and changes in bindin alleles could be explained as secondary by-product of a shift to a new water flow niche (Geyer and Palumbi, 2003). Although there are habitat differences between Eo and Ec (Kelso, 1970; Russo, 1977; Nishihira et al., 1991), there is no shift in bindin alleles. As a result, the bindin shifts described by Geyer and Palumbi (2003) are unlikely to derive solely from external environmental influences and are best explained as reproductive character displacement in sympatry.

Differences in morphological characteristics and fertilization data from the present study along with the recent concordant results of mtDNA differences, bindin sequence divergence and sperm morphology (Geyer and Palumbi, 2003; Landry et al., 2003) indicate that the two populations of black Echinometra in the Central Pacific (Ee) and Western Pacific (Eo) have diverged into two different species. The state of the morphological and genetic traits of the Western Pacific Eo

Table 5 : Comparison of Aristotle's lantern and teeth characteristics of Echinometra oblonga (Eo), Echinometra sp. E (Ee) and Echinometra sp. C (Ec). A total of 25 individual urchins from each species were measured for the Aristotle's lantern and teeth; mean \pm SD in mm including ranges in parentheses

\begin{tabular}{llll}
\hline Aristotle's lantern/teeth & Eo $(\mathrm{mm})$ & Ee $(\mathrm{mm})$ & Ec $(\mathrm{mm})$ \\
\hline Aristotle's lantern diameter (ALD) & $12.52 \pm 0.42^{\mathrm{c}}(11.8-13.5)$ & $14.34 \pm 0.33^{\mathrm{b}}(13.7-14.8)$ & $15.50 \pm 0.37^{\mathrm{a}^{*}}(14.80-16.00)$ \\
Aristotle's lantern length (ALL) & $13.93 \pm 0.33^{\mathrm{c}}(13.40-14.50)$ & $15.78 \pm 0.35^{\mathrm{b}}(15.10-16.20)$ & $17.00 \pm 0.41^{\mathrm{a}}(16.10-17.60)$ \\
Teeth length (TEL) & $2.87 \pm 0.29^{\mathrm{c}}(2.50-3.40)$ & $3.26 \pm 0.32^{\mathrm{b}}(2.70-3.60)$ & $3.60 \pm 0.32^{\mathrm{a}}(3.00-4.20)$ \\
Teeth length (TEW) & $1.22 \pm 0.24^{\mathrm{b}}(0.80-1.70)$ & $1.50 \pm 0.22^{\mathrm{a}}(1.20-1.90)$ & $1.64 \pm 0.20^{\mathrm{a}}(1.30-2.00)$ \\
\hline
\end{tabular}

"Mean values in the same row with common superscripts are not significantly different (Dunn's test, $p>0.05$ )

Table 6: Comparison of spine sizes (length and thickness) of adult Echinometra oblonga (Eo), Echinometra sp. E (Ee) and Echinometra sp. C (Ec). Ten individual urchins from each species were measured with 10 spines from each individual; mean \pm SD in mm including ranges in parentheses

\begin{tabular}{lllll}
\hline Species & Length of spines $(\mathrm{mm})$ & \multicolumn{3}{c}{ Thickness of spines $(\mathrm{mm})$} \\
\cline { 3 - 5 } & & Base & Middle & Tip \\
\hline Eo & $13.42 \pm 0.92^{\mathrm{c}}(11.00-15.70)$ & $1.59 \pm 0.23^{\mathrm{c}}(1.10-2.10)$ & $1.32 \pm 0.22^{\mathrm{c}}(0.80-2.00)$ & $0.57 \pm 0.10^{\mathrm{b}}(0.3-0.8)$ \\
Ee & $18.55 \pm 1.24^{\mathrm{a}}(14.50-22.50)$ & $2.40 \pm 0.24^{\mathrm{a}}(1.70-3.00)$ & $1.94 \pm 0.26^{\mathrm{a}}(1.40-2.70)$ & $0.71 \pm 0.16^{\mathrm{a}}(0.40-1.30)$ \\
Ec & $16.02 \pm 0.64^{\mathrm{b}}(14.40-18.10)$ & $1.97 \pm 0.18^{\mathrm{b}}(1.40-2.40)$ & $1.62 \pm 0.15^{\mathrm{b}}(1.20-2.00)$ & $0.54 \pm 0.08^{\mathrm{b}}(0.30-0.70)$ \\
\hline
\end{tabular}

Mean values in the same column with common superscripts are not significantly different (Dunn's test, $p>0.05$ ) 
Table 7: Comparison of test characteristics of adult Echinometra oblonga (Eo), Echinometra sp. E (Ee) and Echinometra sp. C (Ec). A total of 25 denuded tests from each species were measured for each of the listed test characters; mean \pm SD in mm including ranges in parentheses

\begin{tabular}{llll}
\hline Test characteristics & Eo $(\mathrm{mm})$ & $\operatorname{Ee}(\mathrm{mm})$ & Ec $(\mathrm{mm})$ \\
\hline Length of tests $(\mathrm{TL})$ & $34.94 \pm 2.04^{\mathrm{c}}(30.30-39.40)$ & $37.88 \pm 2.93^{\mathrm{b}}(33.30-44.60)$ & $43.46 \pm 2.58^{\mathrm{a}^{\mathrm{a}}(38.80-49.80)}$ \\
Width of tests (TW) & $28.18 \pm 1.49^{\mathrm{c}}(25.40-32.70)$ & $31.63 \pm 2.16^{\mathrm{b}}(28.40-36.60)$ & $34.91 \pm 2.32^{\mathrm{a}}(29.80-41.60)$ \\
Height of tests (TH) & $20.56 \pm 1.86^{\mathrm{c}}(17.10-25.30$ & $22.62 \pm 1.93^{\mathrm{b}}(18.40-25.70)$ & $25.18 \pm 2.05^{\mathrm{a}}(22.20-28.60)$ \\
Volume of tests (TV) & $20.39 \pm 3.80^{\mathrm{c}}(13.83-31.74)$ & $27.47 \pm 6.09^{\mathrm{b}}(19.36-40.49)$ & $38.44 \pm 6.52^{\mathrm{a}}(25.67-51.24)$ \\
Peristome length (PTL) & $16.06 \pm 1.02^{\mathrm{c}}(14.60-18.20)$ & $17.92 \pm 1.06^{\mathrm{b}}(16.70-19.90)$ & $20.98 \pm 1.16^{\mathrm{a}}(19.20-23.80)$ \\
Peristome Width (PTW) & $16.13 \pm 0.95^{\mathrm{c}}(14.60-18.40)$ & $17.52 \pm 0.93^{\mathrm{b}}(16.00-19.5)$ & $20.43 \pm 6.52^{\mathrm{a}}(18.30-23.10)$ \\
Periproctlength (PPL) & $3.18 \pm 0.38^{\mathrm{c}}(2.50-3.70)$ & $3.86 \pm 0.45^{\mathrm{b}}(3.20-5.10)$ & $4.60 \pm 0.36^{\mathrm{a}}(3.80-5.20)$ \\
Periproct width (PPW) & $2.62 \pm 0.36^{\mathrm{c}}(2.00-3.50)$ & $3.06 \pm 0.28^{\mathrm{b}}(2.60-4.10)$ & $3.50 \pm 0.44^{\mathrm{a}}(2.80-4.50)$ \\
\hline
\end{tabular}

Mean values in the same row with common superscripts are not significantly different (Dunn's test, $p>0.05$ )

Table 8: Proportion of each pore pairs per plate in the adult tests of Echinometra oblonga (Eo), Echinometra sp. E (Ee) and Echinometra sp. C (Ec). A total of 25 denuded clean tests from each species were examined for the listed pore pair ratios; mean \pm SD in percentage including ranges in parentheses

\begin{tabular}{llll}
\hline Pore pairs & Eo $(\%)$ & $\operatorname{Ee}(\%)$ & Ec $(\%)$ \\
\hline One-pore pair & $1.54 \pm 0.59^{\mathrm{a}}(0.46-2.50)$ & $1.44 \pm 0.59^{\mathrm{a}}(0.57-2.40)$ & $1.62 \pm 0.54^{\mathrm{a}^{*}}(0.51-2.78)$ \\
Two-pore pair & $1.90 \pm 0.70^{\mathrm{a}}(0.92-3.97)$ & $1.76 \pm 0.57^{\mathrm{a}}(1.09-2.94)$ & $2.22 \pm 0.63^{\mathrm{a}}(1.40-3.80)$ \\
Three-pore pair & $21.94 \pm 1.28^{\mathrm{c}}(19.47-24.00)$ & $28.95 \pm 1.26^{\mathrm{a}}(26.47-31.41)$ & $24.11 \pm 2.13^{\mathrm{b}}(20.60-27.54)$ \\
Four-pore pair & $47.13 \pm 1.35^{\mathrm{b}}(45.02-50.46)$ & $42.02 \pm 1.39^{\mathrm{c}}(38.04-43.75)$ & $61.18 \pm 1.80^{\mathrm{a}}(57.89-64.28)$ \\
Five-pore pair & $26.64 \pm 1.23^{\mathrm{a}}(24.02-27.64)$ & $24.58 \pm 0.80^{\mathrm{b}}(22.95-16.20)$ & $9.24 \pm 0.74^{\mathrm{c}}(8.08-10.55)$ \\
Six-pore pair & $0.38 \pm 0.36^{\mathrm{a}}(0.00-1.18)$ & $0.56 \pm 0.48^{\mathrm{a}}(0.00-1.63)$ & $0.92 \pm 0.34^{\mathrm{a}}(0.00-1.11)$ \\
Seven-pore pair & $0.22 \pm 0.39^{\mathrm{a}}(0.00-0.91)$ & $0.36 \pm 0.32^{\mathrm{a}}(0.00-1.09)$ & $0.52 \pm 0.39^{\mathrm{a}}(0.00-1.58)$ \\
Eight-pore pair & $0.25 \pm 0.30^{\mathrm{a}}(0.00-0.75)$ & $0.33 \pm 0.34^{\mathrm{a}}(0.00-1.22)$ & $0.39 \pm 0.40^{\mathrm{a}}(0.00-1.43)$ \\
\hline
\end{tabular}

"Mean values in the same row with common superscripts are not significantly different (Dunn's test, $p>0.05$ )

suggests that it is the diverged species. Factors driving the divergence of Eo in the Western Pacific are yet to be determined. However, the closer affinities of majority of the morphological characteristics, larger egg and slender sperm morphology and bindin sequence differences are correlated with the presence of E. sp. C, a species that generally occupies similar habitats on the Western Pacific reefs (Nishihira et al., 1991; Uehara et al., 1996; Geyer and Palumbi, 2003). When they co-occur, Eo has been reported to occupy stronger wave action areas than Ec (Arakaki and Uehara, 1991). The derived sperm and egg morphology might then be an adaptation to this habitat of higher wave action. This hypothesis is supported by the similar elongated sperm morphology encountered in Colobocentrotus mertensii (Arakaki and Uehara, 1989), another member of the family Echinometridae inhabiting high wave-action areas. It is also very interesting that the egg diameter and sperm head length of Okinawan Echinometra including Hawaiian Ee increases in order of $\mathrm{Ea}<\mathrm{Em}<\mathrm{Ec}<\mathrm{Ee}<\mathrm{E}$, which correlates with the relative exposure of these species to wave action (Nishihira et al., 1991; Aslan and Uehara, 1997; Aslan et al., 1999; Arakaki et al., 1998; Rahman et al., 2001, 2004; Mita et al., 2002; Rahman and Uehara, 2004). Longer sperm could be better at fertilizing bigger eggs, as proposed by Raff et al. (1990) which in turn could be better and more resistant in higher wave action. Larger eggs are also thought to act as better targets for sperm, thereby enhancing fertilization success (Levitan, 1993, 1998 a,b; Rahman et al., 2002).

Based on the results obtained from the present study, the detailed fertilization and morphological characteristics, it appears that Ee evolved on Hawaii (Central Pacific) from a colonization in the past of a population of Eo (perhaps during a change in the currents that allowed an eastern dispersion of larvae), and then more recently, a population of Ee became established on some portion of the Western Pacific (such as Okinawa) and evolved into Ec and dispersed in the Western Pacific. These changes resulted in reproductive isolation and speciation between $E$. sp. $E$ currently found in the Central Pacific and the new species in the Western Pacific, described as E. oblonga (Arakaki and Uehara, 1999), diverged within the past 250,000 years (Landry et al., 2003). Although E. sp. E deserves a species name, the origin of the species is not clearly known, and therefore attributing a new species name will require further investigation.

\section{Acknowledgments}

We are much indebted to Japan Society for Promotion of Science (JSPS) and to the Ministry of Science, Technology and Innovation (MOSTI), Malaysia for financial supports under the "ScienceFund" grant vide Project No. 04-01-04-SF2227 through 
the Universiti Putra Malaysia (UPM) to successfully complete this work.

\section{References}

Amy, R.L.: Gamete sizes and developmental time tables of five tropical sea urchins. Bull. Mar. Sci. , 33, 173-176 (1983).

Arakaki, Y.: The black Echinometra distributed in the Indo-West Pacific: A species complex. In: Echinoderm 2000 (Ed: M.F. Barker). Swets and Zeitlinger, Lisse, The Netherlands, pp. 407-412 (2000).

Arakaki, Y. and T. Uehara: Comparative external morphology on the spermatozoa of four species, the family of Echinometridae, found on Okinawan reef flat. Zool Sci., 6, 1221 (1989).

Arakaki, Y. and T. Uehara: Physiological adaptation and reproduction of the four types of Echinometra mathaei (Blainville). In: Biology of Echinodermata (Eds: T. Yanagisawa, I. Yasumasu, C. Oguro, N. Suzuki and T. Motokawa). A.A. Balkema, Rotterdam, pp. 105-111 (1991).

Arakaki, Y. and T. Uehara: Morphological comparison of black Echinometra individuals among those in the Indo-west Pacific. Zool. Sci., 16, 551-558(1999).

Arakaki, Y., T. Uehara and I. Fagoone: Comparative studies of the genus Echinometra from Okinawa and Mauritius. Zool. Sci., 15, 159-168 (1998).

Aslan, L.M. and T. Uehara: Hybridization and $F_{1}$ backcrosses between two closely related tropical species of sea urchins (genus Echinometra) in Okinawa. Invert. Reprod. Develop., 31, 319-324 (1997).

Aslan, L.M., M.A. Rahman and T. Uehara: Relationship between egg size and larval size of two closely related species of sea urchins genus Echinometra and the egg size effects to the larval size of their reciprocal hybrids. Biol. Mag. Okinawa, 37, 67-93(1999).

Banks, M.A., D.J. McGoldrick, W. Borgeson and D. Hedgecock: Gametic incompatibility and genetic divergence of Pacific and Kumamoto oysters, Crassostrea gigas and C. sikamea. Mar. Biol., 121, 127-135(1994).

Biermann, C.H.:The molecular evolution of sperm bindin in six species of sea urchins (Echinoida: Strongylocentrotidae). Mol. Biol. Evol., 15, 1761-1771 (1998).

Biermann, C.H., J.A. Marks, A.C.E.S. Vilela-Silva, M.O. and P.A.S. Castro Mourão: Carbohydrate-based species recognition in sea urchin fertilization: Another avenue for speciation. Evol. Develop., 6, 353-361 (2004).

Branham, J.M.: Comparative fertility of gametes from six species of sea urchins. Biol. Bull., 142, 385-396 (1972).

Brown, W.L. and E.O. Wilson: Character displacement. Syst. Zool., 7, 49-64 (1956).

Bush, G.L.: Sympatric host race formation and speciation in frugivorous flies of genus Rhagoletis (Diptera, Tephritidae). Evolution, 23, 237-251 (1969).

Bush, G.L.: Modes of animal speciation. Annu. Rev. Ecol. Syst., 6, 339-364 (1975).

Bush, G.L. and J.J. Smith: The genetics and ecology of sympatric speciation: A case study. Res. Popul. Ecol., 40, 175-187 (1998).

Byrne, M. and M.J. Anderson: Hybridization of sympatric Patiriella species (Echinodermata: Asteroidea) in New South Wales. Evolution, 48, 564-576 (1994).

Debenham, P., M.A. Brzezinski and K.R. Foltz: Evaluation of sequence variation and selection in the bindin locus of the red sea urchin,
Strongylocentrotus franciscanus. J. Mol. Evol., 51, 481-490 (2000).

Geyer, L.B. and S.R. Palumbi: Reproductive character displacement and the genetics of gamete recognition in tropical sea urchins. Evolution, 57, 1049-1060 (2003).

Grant, P.: Convergent and divergent character displacement. Biol. J. Linn. Soc., 4, 39-64 (1972).

Kaneshiro, K.: Sexual isolation, speciation and the direction of evolution. Evolution, 34, 437-444 (1980).

Kornerup, A. and J.H. Wanscher: Maethuen Handbook of Color. 3rd Edn., London: Eyre Mathuen Ltd., p. 259 (1978).

Landry. C., L.B. Geyer, Y. Arakaki T. Uehara and S.R. Palumbi: Recent speciation in the Indo-West Pacific: Rapid evolution of gamete recognition and sperm morphology in cryptic species of sea urchin. Proc. R. Soc. Lond. B., 270, 1839-1847 (2003).

Leighton, D.L. and C.A. Lewis: Experimental hybridization in abalone. Int. J. Invertebr. Reprod. Dev., 5, 273-282 (1982).

Lessios, H.A. and C.W. Cunningham: Gametic incompatibility between species of the sea urchin genus, Echinometra on the two sides of the Isthmus of Panama. Evolution, 44, 933-941 (1990).

Levtan, D.R.: The importance of sperm limitation to the evolution of egg size in marine invertebrates. Am. Nat., 141, 517-536 (1993).

Levitan D.R.: Does Bateman's principle apply to broadcast-spawning organisms? Egg traits influence in situ fertilization rates among congeneric sea urchins. Evolution, 52, 1043-1056 (1998a).

Levitan D.R.: Sperm limitation, gamete competition, and sexual selection in external fertilizers. In: Sperm Competition and Sexual Selection (Eds: T.R. Birkhead and A.P. Moller). Academic Press, San Diego, pp. 175-217 (1998b).

Levitan, D.R.: The relationship between conspecific fertilization success and reproductive isolation among three congeneric sea urchins. Evolution, 56, 1599-1609 (2002).

Marshal, D.C. and J.R. Cooley: Reproductive character displacement and speciation in periodical cicadas, with description of a new species, 13-year Magicicada neotredecim. Evolution., 54, 1313-1325 (2000).

Matsuoka, N. and T. Hatanaka: Molecular evidence for the existence of four sibling species within the sea urchin, Echinometra mathaei in Japanese waters and their evolutionary relationships. Zool. Sci., 8, 121-133 (1991).

Mayr, E.: Geographic speciation in echinoids. Evolution, 8, 1-18 (1954).

McCartney, M.A. and H.A. Lessios: Quantitative analysis of gametic incompatibility between closely related species of neotropical sea urchins. Biol. Bull., 202, 166-181 (2002).

McCartney, M.A., G. Keller and H.A. Lessios: Dispersal barriers in tropical oceans and speciation in Atlantic and eastern Pacific Sea urchins of the genus Echinometra. Mol. Ecol., 9, 1391-1400 (2000).

Metz, E.C. and S.R. Palumbi: Positive selection and sequence rearrangements generate extensive polymorphism in the gamete recognition protein bindin. Mol. Biol. Evol., 13, 397-406 (1996).

Metz, E.C., R.E. Kane, H. Yanagimachi and S.R. Palumbi: Fertilization between closely related sea urchins is blocked by incompatibilities during sperm-egg attachment and early stages of fusion. Biol. Bull., 187, 23-34 (1994).

Metz, E.C., G. Gomez-Gutierrez and V.D. Vacquier: Mitochondrial DNA and bindin gene sequence evolution among allopatric species of the sea urchin genus Arbacia. Mol. Biol. Evol., 15, 185-195(1998).

Mita, M., T. Uehara and M. Nakamura: Comparative studies on the 
energy metabolism in spermatozoa of four closely related species of sea urchins (genus Echinometra) in Okinawa. Zool. Sci., 19, 419-427 (2002).

Nishihira, M., Y. Sato, Y. Arakaki and M. Tsuchiya: Eological distribution and habitat preference of four types of Echinometra mathaei on Okinawan coral reef. In: Biology of Echinodermata (Eds: T. Yanagisawa, I. Yasumasu, C. Oguro, N. Suzuki and T. Motokawa). A.A. BalkemaRotterdam, pp. 91-104 (1991).

Palumbi, S.R.: What can molecular genetics contribute to marine biogeography? An urchin's tale. J. Exp. Mar. Biol. Ecol., 203, 75-92 (1996).

Palumbi, S.R.: Molecular biogeography of the Pacific. Coral Reefs, 16, S47-S52 (1997).

Palumbi, S.R.: Species formation and the evolution of gamete recognition loci. In: Endless Forms: Species and Speciation (Eds: D.J. Howard and S.H. Berlocher). Oxford University Press, New York, pp. 271-278(1998).

Palumbi, S.R. and E.C. Metz: Strong reproductive isolation between closely related tropical sea urchins (Genus Echinometra). Mol. Biol. Evol., 8, 227-239(1991).

Palumbi, S.R., G. Grabowsky, T. Duda, L. Geyer and N. Tachino: Speciation and population genetic structure in tropical Pacific sea urchins. Evolution, 5, 1506-1517 (1997).

Raff, R.A., L. Harlands and V.B. Morris: Evolutionary modification of echinoid sperm correlates with developmental mode. Dev. Growth Differ., 32, 283-291 (1990).

Rahman, M.A. and T. Uehara: $F_{1}$ and $F_{2}$ backcrosses in the hybrids between two unnamed genetically distinct species of tropical sea urchins, Echinometra sp. A and Echinometra sp. C. Pak. J. Biol. Sci., 6, 1163-1175(2003).

Rahman, M.A. and T. Uehara: Interspecific hybridization and backcrosses between two sibling species of Pacific sea urchins (Genus Echinometra) on Okinawan intertidal reefs. Zool. Stud., 43, 93-111 (2004).

Rahman, M.A., T. Uehara and L.M. Aslan: Comparative viability and growth of hybrids between two sympatric species of sea urchins (Genus Echinometra) in Okinawa. Aquaculture, 183, 45-56 (2000).

Rahman, M.A., T. Uehara and J.S. Pearse: Hybrids of two closely related tropical sea urchins (Genus Echinometra): Evidence against postzygotic isolating mechanisms. Biol. Bull., 200, 97-106 (2001).

Rahman, M.A., T. Uehara and S.M. Rahman: Effects of egg size on fertilization, fecundity and offspring performance: A comparative study between two sibling species of tropical sea urchins (Genus Echinometra). Pak. J. Biol. Sci., 5, 114-121 (2002).

Rahman, M.A., T. Uehara and J.S. Pearse: Experimental hybridization between two recently diverged species of tropical sea urchins, Echinometra mathaei and Echinometra oblonga. Invert. Reprod. Develop., 45, 1-14 (2004).

Rahman, M.A., T. Uehara, A. Arshad, F.M. Yusoff and M.N. Shamsudin: Absence of postzygotic isolating mechanisms: Evidence from experimental hybridization between two species of tropical sea urchins. J. Zhejiang Univ. Sci. B, 13, 797-810 (2012).

Rice, W.R. and G.W. Salt: The evolution of reproductive isolation as a correlated character under sympatric conditions: Experimental evidence. Evolution, 44,1140-1152 (1990).

Rundle, H.D. and D. Schluter: Reinforcement of strickleback mate preferences: Sympatry breeds contempt. Evolution, 52, 200-208 (1998).

Rundle, H.D., L. Nagel, J.W. Boughman and D. Schluter: Natural selection and parallel speciation in sympatric stricklebacks. Science, 287, 306-308 (2000).

Russo, A.R.: Water flow and the distribution and abundance of Echinoids (Genus Echinometra) on a Hawaiian reef. Aus. J. Mar. Freshwat. Res., 28, 693-702 (1977).

Slatkin, M.: Pleiotropy and parapatric speciation. Evolution, 36, 263-270 (1982).

Simon, C., J. Tang, S. Daiwadi, G. Staley, J. Deniega and T.R. Unnasch: Genetic evidence for assertive mating between 13-year cicadas and sympatric "17-year cicadas with 13-year life cycles" provides support for allocronic speciation. Evolution, 54, 1326-1336 (2000).

Strathmann, R.R.: On barriers to hybridization between Strongylocentrotus droebachiensis (O.F. Muller) and S. pallidus (G.O.Sars). J. Exp. Mar. Biol. Ecol., 55, 39-47 (1981).

Tsuchiya, M. and M. Nishihira. Ecological distribution of two types of sea urchin, Echinometra mathaei (Blainville), on Okinawan reef flat. Galaxea, 3, 131-143(1984).

Uehara, T.: Speciation in Echinometra mathaei. Iden, 44, 47-53 (in Japanese).

Uehara, T., H. Asakura and Y. Arakaki: Fertilization blockage and hybridization among species of sea urchins. In: Advances in Invertebrate Reproduction (Eds: M. Hoshi and O. Yamashita). Elsevier, Amsterdam, pp. 305-310 (1990).

Uehara T., M. Shingaki, K. Taira, Y. Arakaki and H. Nakatomi: Chromosome studies in eleven Okinawan species of sea urchins, with special reference to four species of the Indo-Pacific Echinometra. In: Biology of Echinodermata (Eds: T. Yanagisawa, I. Yasumasu, C. Oguro, N. Suzuki and T. Motokawa). A.A. Balkema Rotterdam, pp. 119-129 (1991).

Uehara, T., J. Tsukahara and M. Tsukashima: Distribution and characteristics of sea urchin genus Echinometra from Palau. Kagoshima University Research Centre South Pacific Occasional Papers, pp. 55-59 (1996).

Zar, J.H.: Biostatistical analysis. $3^{\text {rd }}$ Edn., Prentice Hall International, Inc., Upper Saddle River, NJ (1996).

Zigler, K.S. and H.A. Lessios: Evolution of bindin in the Pantropical Sea urchin Tripneustes: Comparisons to bindin of other genera. Mol. Biol. Evol., 20, 220-231 (2003).

Zigler, K.S. and H.A. Lessios: Speciation on the coasts of the new world: Phylogeography and the evolution of bindin in the sea urchin genus Lytechinus. Evolution, 58, 1225-1241 (2004).

Zigler, K.S., E.C. Raff, E. Popodi, R.A. Raff and H.A. Lessios: Adaptive evolution of bindin in the genus Heliocidaris is correlated with the shift to direct development. Evolution, 57, 2293-2302 (2003) 